\title{
A Supramolecular Hydrogel as a Reusable Catalyst for the Aldol Reaction
}

Key words

hydrogels

heterogeneous catalysis

aldol reaction

Preparation of hydrogel-1:

L-proline

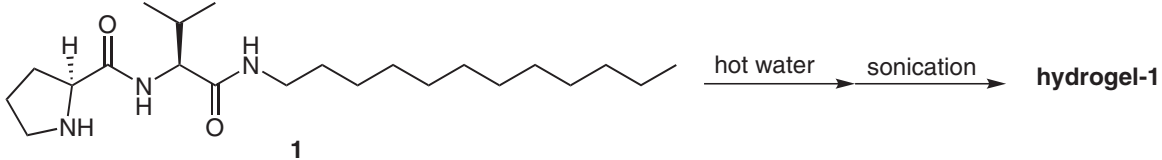

Aldol reaction:<smiles>O=C1CCCCC1</smiles>

(20 equiv)<smiles>O=Cc1ccc([N+](=O)[O-])cc1</smiles>

(1 equiv)

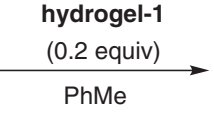

(0.2 equiv)

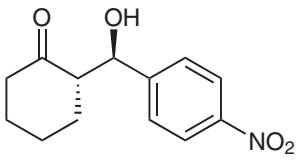

Reuse and recycling of hydrogel-1:

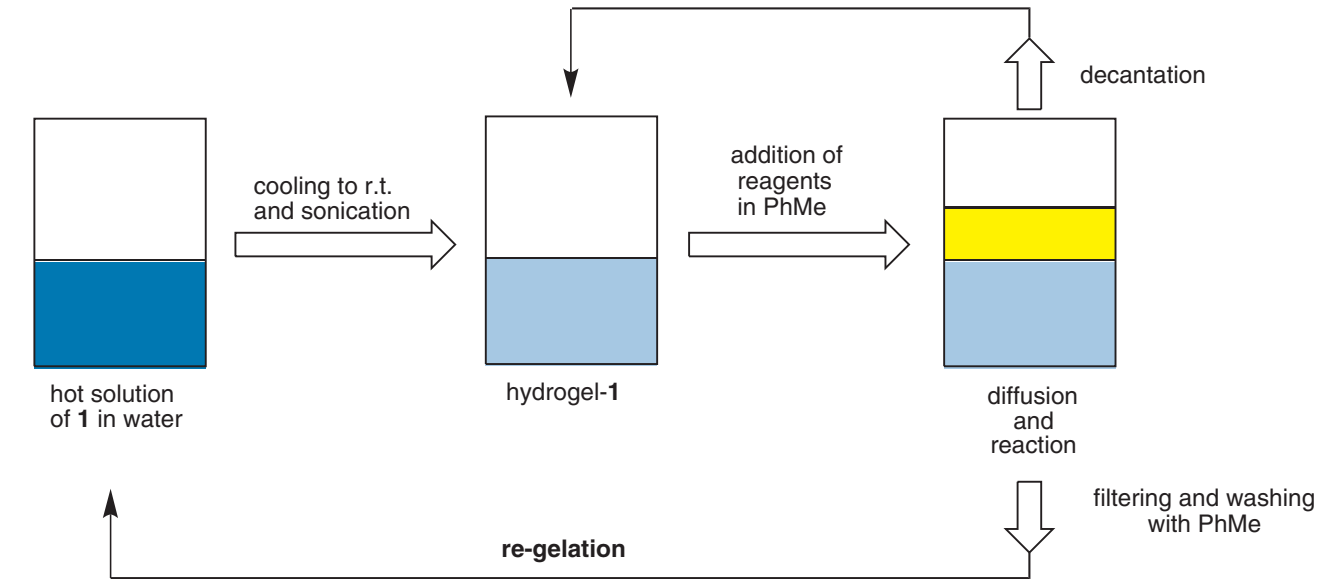

Significance: The aldol reaction using L-prolinebased supramolecular hydrogel as an efficient heterogeneous organocatalyst was described. Thus, 4-nitrobenzaldehyde $(0.16 \mathrm{mmol})$ and cyclohexanone $(155 \mu \mathrm{L})$ in $1 \mathrm{~mL}$ of toluene was add ed on the top of the hydrogel at $5{ }^{\circ} \mathrm{C}$ over 24 hours to give the aldol product ( $98 \%$ yield, anti/ $s y n=92: 8,88 \%$ ee). After decantation of the organic layer, the hydrogel did not seem macroscopically affected and was reused for two additional runs without any loss of catalytic activity ( $2^{\text {nd. }}$ : $>99 \%$ yield, anti/syn $=93: 7,87 \%$ ee, $3^{\text {rd. }}$. $>99 \%$ yield, anti/syn $=92: 8,90 \%$ ee, respectively).
Comment: The morphology of the gel was observed by scanning electron microscopy (SEM), revealing the presence of a network of ribbons of several $\mu \mathrm{m}$ in length and less than $300 \mathrm{~nm}$ in width. X-ray powder diffraction of the xerogel was consistent with a lamellar structure in which compound $\mathbf{1}$ formed a bilayer with intercalation of the alkyl tails. The temperature (filtering, washing with toluene, and re-gelating) and $\mathrm{pH}$ (acidification, washing with toluene, neutralizing and re-gelating) as well as the responsiveness of the hydrogel allowed for its complete recovery and regeneration. 